Editorial

\title{
Civic Organizations and Digital Technologies in an Age of Distrust
}

\author{
Eric Gordon \\ Engagement Lab, Emerson College, Boston, MA 02116, USA; E-Mail: eric_gordon@emerson.edu
}

Submitted: 26 July 2019 | Published: 6 August 2019

\begin{abstract}
How are civic organizations using new and emerging technologies to adapt to a new context of distrust? This editorial contextualizes new research on trust and organizations in civic life and identifies a number of key factors contributing to the urgency of the work. As publics grow increasingly suspicious of the institutions that mediate civic life, including news, government and civil society, organizations are adopting new tactics to accommodate this new reality.
\end{abstract}

\section{Keywords}

civic organizations; distrust; fake news; information communication technology; innovation; social infrastructure

\author{
Issue \\ This editorial is part of the issue "Civic Organizations and Digital Technologies in an Age of Distrust", edited by Eric Gordon \\ (Emerson College, USA). \\ (C) 2019 by the author; licensee Cogitatio (Lisbon, Portugal). This article is licensed under a Creative Commons Attribu- \\ tion 4.0 International License (CC BY).
}

Recent years have brought to the foreground concerns about the motivations and legitimacy of the institutions that mediate public life, including news, government and civil society (Knight Commission on Trust, Media and Democracy, 2019). As new voices, previously excluded from popular discourse (including women, immigrants, and people of color) are amplified through technical and social means, the institutions that once so effectively served the center are being forced to open up and reorganize. Major news organizations like the New York Times and the $B B C$ served "the public" well, when that public was accepted as a narrowly conceived of majority. But as contemporary digital technology and culture have enabled new voices and new influence (Allen \& Light, 2015), those same news organizations are challenged to become more broadly representative, with cries from the left that they have systematically ignored and excluded women and communities of color, and cries from the right that they serve a globalist establishment that is ignoring the forgotten (white) center. Donald Trump, the president of the United States, is fond of referring to the "fake New York Times," as the enemy of the people. In doing so, he associates "people" with what was once comfortably referred to as the "public." Major news outlets along with the thousands of smaller organizations that comprise the institution of news, are feeling pressure to adapt and are taking a range of actions to do so. Some of these actions include building and adopting new technologies, and others include making time and space to forge new, and support existing, relationships (Lawrence, Gordon, DeVigal, Mellor, \& Elbaz, 2019).

The same is true for government and civil society organizations who have been comfortable with business as usual and are now feeling the pressure to become more responsive to emerging publics. In government, as citizens have come to expect better service delivery, more equitable distribution of services, and proper representation, organizations are being asked to do things differently. The resulting practices are messy, not at all consistent, and in some cases, merely placating. Hiring consultants to better "engage the public" is not the same as fostering trust through relationships and trustworthy transactions. As a means of transforming how publics interface with government, some organizations are enthusiastically pursuing new innovation offices (Jacob, 2015), and some are hiring better and more engagement practitioners to realign how the government speaks and listens (Gordon, 2017). In most cases, these practices are well intentioned and fraught.

This thematic issue of Media and Communication brings together research on how organizations are responding to this emergent context of distrust through 
the use and/or critical engagement of digital technologies. Most of the articles included here focus on how individuals are negotiating programmatic needs of organizations with the practical adoption of new tools and approaches. Whether it's the use of social media in a local non-profit, or the design and implementation of an open data repository in government, each of the examples in this issue is implemented with the sensitivity of needing to create or maintain trust with the publics that organizations serve. This set of concerns with the adoption of technology is relatively new. While scholars have long pointed out the challenges of integrating new technologies in organizational structures (DeScantis \& Poole, 1994), never before have those challenges focused so intensely on building trust, not just with the immediate end users, but with the organization's broader constituencies. How organizations in the civic space shift and accommodate new tools and processes are increasingly guided by non-instrumental factors. In other words, it is not just about what new technologies do for organizational systems, but how they support or erode systems of trust (Wells, 2015). Recent scholarship has identified a variety of contexts and situations where these $d y$ namics play out, particularly in government (Bannister \& Connolly, 2014). Klinenberg (2018) looks outside of government organizations to spaces within cities. He describes social infrastructure, or the actual spaces that support relation and trust-building, including libraries, meeting halls, and other spaces designed for interaction. And Gordon and Mugar (in press) introduce the concept of "meaningful inefficiencies" that extends the concept of social infrastructure to any space (physical, social, digital, etc.) that is deliberately designed to enable civic interaction and support relation, often in contrast to the logics guiding technological progress.

This short issue includes five articles that seek to capture emerging tactics of organizations to engage in what Peter Levine calls "civic renewal" (Levine, 2013). The first, by Eric Gordon and Rogelio Lopez (2019), is entitled "The Practice of Civic Tech: Tensions in the Adoption and Use of New Technologies in Community-Based Organizations". This article presents ethnographic research with an influential community organization in Boston, United States, that examines how people within the organization think about and put new technologies into use. The article points out the tensions that emerge for individual practitioners and for the organization as a whole as technologies are adopted. Notably, the authors focus on the tension between function and representation, or what tech actually does versus the optics of its use. The next article by Mariam Asad and Chris Le Dantec (2019) is called "'This is Shared Work': Negotiating Boundaries in a Social Service Intermediary Organization". Similarly, this research looks at technology adoption and use in an organization in the American south focused on criminal justice reform. But instead of looking at internal dynamics alone, Asad and Le Dantec (2019) examine the interactions between the organization and the researchers. Ulti- mately, they surface the limitations of participatory work for issue-based organizations committed to progressive social change, further challenging the notion that technologies can capture lost trust.

The next set of articles ask different questions. Rajab Ritonga and Iswandi Syahputra (2019) look at citizen journalism in Indonesia, specifically as it manifests on Twitter. In their article "Citizen Journalism and Public Participation in the Era of New Media in Indonesia: From Street to Tweet," they interrogate how people come to trust information shared on Twitter and why mainstream news outlets are increasingly criticized as being too closely aligned with the state. Their insights into information ecosystems, and specifically how trust is negotiated between existing and emergent information channels is incredibly important for the larger understanding of how individuals and organizations make decisions about what's trustworthy and what's not. Nathan Sanders' (2019) article entitled "AMEND: Open Source, Data Driven Oversight of Water Quality in New England," is a case study of an open source repository for environmental data. This article examines the implementation of an open data resource and points to the way that data transparency and access can overcome some of the technical and social barriers to building trust. The article describes in practical detail how the tool was built and the challenges of uptake across a range of different interest groups and organizations.

The final article in this issue is by Eric Corbett and Chris Le Dantec (2019). Their article, "'Removing Barriers' and 'Creating Distance': Exploring the Logic of Efficiency and Trust in Civic Technology," explores the contrast between trust building and efficiency. Based on ethnographic work within government organizations, they explore how civic technologies intended to remove barriers and increase efficiency can sometimes run counter to the work of relationship and trust building. They conclude with suggested processes whereby government organizations can centralize the goal of actively building trust while adopting and implementing civic technologies. They touch on the design challenge of creating meaningful inefficiencies and demonstrate the intensity of work required by dedicated practitioners to prioritize relationship building when the dominant logic of technology encourages the fastest path to completing transactions.

Together, the five articles in this thematic issue examine multiple dimensions of the task of building trust in civic organizations, and the complicating factors introduced by the adoption and implementation of digital technologies. From news to government and civil society organizations, the use of technology to facilitate civic renewal is complex and often counter-intuitive. Each one of the articles collected here illustrate that digital technologies can aid civic organizations in their programmatic work, but, if not thoughtfully implemented, can erode the institutional values on which the organization needs to stand. 


\section{Conflict of Interests}

The author declares no conflict of interests.

\section{References}

Allen, D., \& Light, J. (Eds.). (2015). From voice to influence: Understanding citizenship in a digital age. Chicago, IL: University of Chicago Press.

Asad, M., \& Le Dantec, C. A. (2019). "This is shared work:" Negotiating boundaries in a social service intermediary organization. Media and Communication, $7(3)$, 69-78.

Bannister, F., \& Connolly, R. (2014). ICT, public values and transformative government: A framework and programme for research. Government Information Quarterly, 31(1), 119-128.

DeSanctis, G., \& Poole, M. S. (1994). Capturing the complexity in advanced technology use: Adaptive structuration theory. Organization Science, 5(2), 121-147.

Corbett, E., \& Le Dantec, C. A. (2019). 'Removing barriers' and 'creating distance': Exploring the logic of efficiency and trust in civic technology. Media and Communication, 7(3), 104-113.

Gordon, E., \& Lopez, R. A. (2019). The practice of civic tech: Tensions in the adoption and use of new technologies in community based organizations. Media and Communication, 7(3), 57-68.

Gordon, E. (2017). Accelerating public engagement: Roadmap for local government (Living Cities white paper series). New York, NY: Living Cities.

Gordon, E., \& Mugar, G. (in press). Meaningful inefficien- cies: Transforming civic life through play and care. New York, NY: Oxford University Press.

Jacob, N. (2015). Guide for embedding breakthrough innovation in local government (Living Cities white paper series). New York, NY: Living Cities.

Klinenberg, E. (2018). Palaces for the people: How social infrastructure can help fight inequality, polarization, and the decline of civic life. New York, NY: Crown Books.

Knight Commission on Trust, Media and Democracy. (2019). Crisis in democracy: Renewing trust in America. Washington, DC: The Aspen Institute. Retrieved from http://csreports.aspeninstitute.org/KnightCommission-TMD/2019/report

Lawrence, R. G., Gordon, E., DeVigal, A., Mellor, C., \& Elbaz, J. (2019). Building engagement: Supporting the practice of relational journalism. Portland, OR: Agora Journalism Center. Retrieved from http://bit. ly/building-engagement

Levine, P. (2013). We are the ones we have been waiting for: The promise of civic renewal in America. New York, NY: Oxford University Press.

Sanders, N. (2019). AMEND: Open source, data-driven oversight of water quality in New England. Media and Communication, 7(3), 91-103.

Ritonga, R., \& Syahputra, I. (2019). Citizen journalism and public participation in the era of new media in Indonesia: From street to tweet. Media and Communication, 7(3), 79-90.

Wells, C. (2015). The civic organization and the digital citizen: Communicating engagement in the networked age. New York, NY: Oxford University Press.

\section{About the Author}

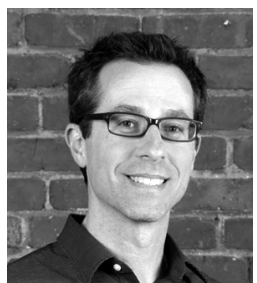

Eric Gordon is Professor of Civic Design and the Director of the Engagement Lab at Emerson College in Boston. His research focuses on the transformation of public life and governance in digital culture, and the incorporation of play into collaborative design processes. He is the editor of Civic Media: Technology, Design, Practice (MIT Press, 2016) and the author of Meaningful Inefficiencies: Transforming Civic Life Through Play and Care (Oxford University Press, 2020). 